\title{
Peroneal artery entrapment syndrome (PRAES): a rare cause of ischaemic toes
}

\author{
Alfred Bingchao Tan, ${ }^{1}$ Wesley Stuart, ${ }^{2}$ Giles Roditi ${ }^{3}$
}

\begin{abstract}
${ }^{1}$ Department of Radiology, Queen Elizabeth University Hospital, Glasgow, UK ${ }^{2}$ Department of Vascular Surgery, Queen Elizabeth University Hopsital, Glasgow, UK ${ }^{3}$ Department of Radiology, Glasgow Royal Infirmary
\end{abstract}

\section{Correspondence to} Dr Alfred Bingchao Tan, alfred.research@gmail.com

Accepted 11 November 2018

Check for updates

(C) BMJ Publishing Group Limited 2019. No commercial re-use. See rights and permissions. Published by BMJ.

To cite: Tan AB, Stuart W,
Roditi G. BMJ Case Rep
2019;12:e227353.
doi:10.1136/bcr-2018-
227353

\begin{abstract}
SUMMARY
A 75-year-old man presenting with intermittent discolouration of his left toes was referred to vascular surgery with suspicion of embolic vascular disease. A contrast-enhanced MR angiogram was performed which revealed bilateral dominant peroneal arteries (PRAs). There was evidence of short atherosclerotic stenosis directly at the point where the left PRA passes through the tibiofibular interosseous membrane which we postulate to be the source of the emboli. We present what is believed to be the first reported case of PRA entrapment complicated by distal toe emboli.
\end{abstract}

\section{BACKGROUND}

Atherosclerotic disease is the most common condition encountered in vascular practice. Vascular compression or entrapment is a much more uncommon pathology that mimics the symptomatology seen in atherosclerotic diseases. ${ }^{1}$ Some of the more commonly known vascular compression conditions include thoracic outlet syndrome and popliteal artery entrapment syndrome. In this article, we present a case of bilateral dominant peroneal arteries (PRAs) which are impinged on by the interosseous membranes distally and complicated by distal toe embolism. This report reviews a rare diagnosis that should be considered in patients who present with embolic phenomena and highlights the role of advanced MR angiography (MRA) techniques in delineating variant infrainguinal arterial anatomy and making the diagnosis.

\section{CASE PRESENTATION}

A 75-year-old man with a previous history of myocardial infarction more than 10 years previously and subsequent coronary artery bypass presented to the vascular surgery clinic with a 5 -week history of a red tip to his left second toe. He denied any specific injury or particular discomfort in the toe and systemically he felt well. On clinical examination, there was erythema over the distal aspect of his left second toe with sluggish capillary refill. Palpable dorsalis pedis and posterior tibial pulses were present in both of his feet but his left foot felt cooler to touch compared with the right foot. There was no evidence of elevation pallor.

\section{INVESTIGATIONS}

An abdominal ultrasound scan which had been requested by the general practitioner to exclude an abdominal aortic aneurysm as a source of distal emboli was unproductive with a normal calibre aorta. His echocardiogram shows mild concentric left ventricular hypertrophy with good systolic contraction, normal valve function and no intracardiac thrombi.

MRA which was performed following his vascular clinic review confirmed normally patent aortoiliac and femoropopliteal arterial segments with no atherosclerotic disease. Below the knee, there was three vessel crural run-off. However, there was an anatomical variation in the form of bilateral dominant PRAs with distal pinch stenosis (figure 1) and hypoplastic anterior tibial arteries (ATA); the latter not reaching the feet. On the MRA high-resolution extended phase imaging sequences, both PRAs were demonstrated to course through the distal tibiofibular interosseous membrane before continuing as the dorsalis pedis arteries (figure 2). At the point of crossing the interosseous membrane, the PRAs were focally narrowed by with signs of atherosclerotic plaque disease. The dorsalis pedis arteries were patent bilaterally beyond these short stenoses.

\section{OUTCOME AND FOLLOW-UP}

The patient was reviewed back at the clinic with the results of his scan when it was clear that he had a further recent embolic episode affecting his left hallux. In view of his negative screening tests and widely patent upstream vessels, it was postulated that embolic source was from the atherosclerotic changes present in his left PRA secondary to relative entrapment by the interosseous membrane.

The patient was already on aspirin therapy for his ischaemic heart disease but the decision was made to switch him to clopidogrel on the basis that he had embolic events despite the aspirin. He was seen in clinic 2 months later and reports that symptoms have completely resolved.

\section{DISCUSSION}

Conventional anatomical division of the popliteal artery involves bifurcation of the vessel below the level of the tibial plateau into the ATA and tibioperoneal artery (TPA). The TPA continues over a short length of around $2 \mathrm{~cm}$ before dividing into the PRA and the posterior tibial artery (PTA). The ATA usually continues into the foot as dorsalis pedis artery, the PTA supplies the medial plantar artery in the foot and the PRA supplies muscular branches not usually reaching the foot. Variability in the division pattern can be accounted for by sporadic combinations of abnormal vessel fusion, segmental 


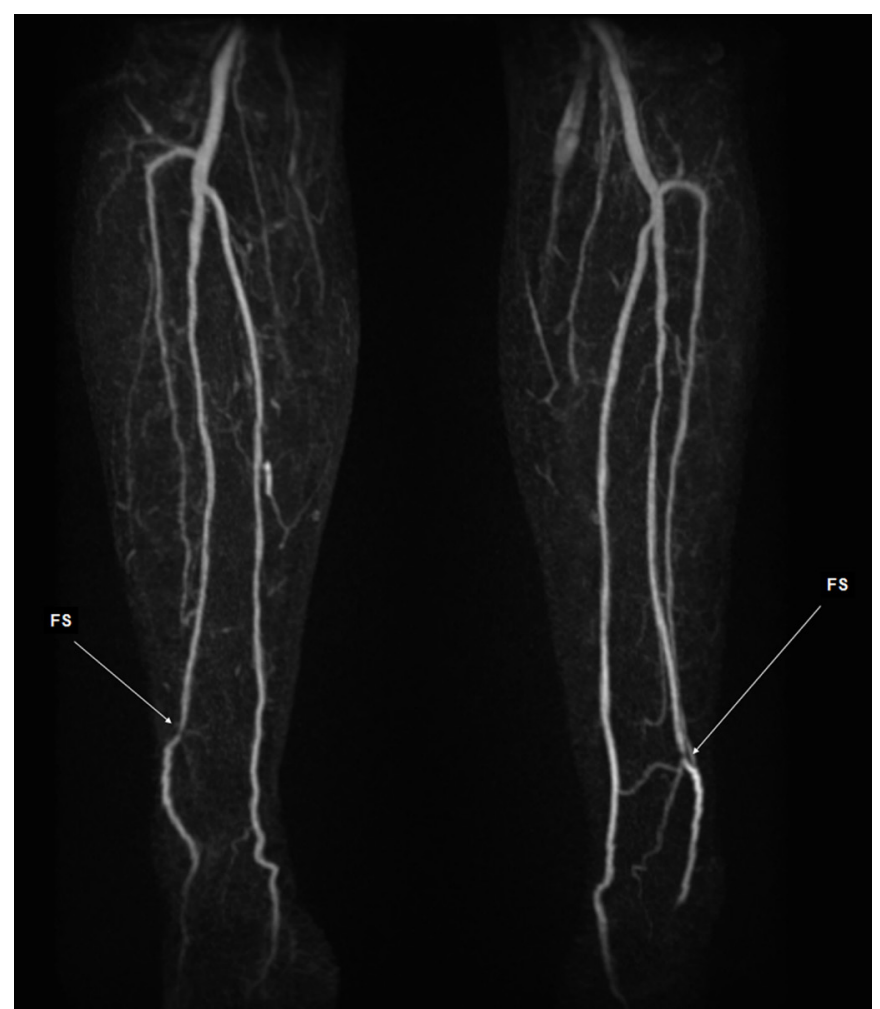

Figure 1 Coronal maximium intensity projection Time-Resolved Angiography With Stochatic Trajectories MR angiography—bilateral dominant peroneal artery with distal focal stenosis (FS, white arrows).

regression and persistence of the primitive sciatic and femoral arteries during fetal development. In the literature, the variability of the branching pattern has been reported to be in the range of $7.4 \%$ to $17.6 \% .^{2}$

The most modern classification of the popliteal artery branching pattern is proposed by Kim et al based on a modification of Lippert's system which considers a third category of patients with normal branching patterns but ATA and PTA which are absent or hypoplastic. ${ }^{34}$ Our patient has a type IIIB anatomy in both calves whereby the ATA is hypo/ aplastic and is replaced by the dominant hypertrophied PRA which traverses the distal interosseous membrane of the leg (middle tibiofibular ligament) to form the dorsalis pedis artery in the foot. A large patient cohort study by Sung-won et al shows that this particular vessel branching pattern occurs in $1.4 \%$ of the studied population. ${ }^{5}$

We believe this to be the first reported case of a peroneal artery entrapment syndrome (PRAES) with secondary distal embolic complication of the toes. The pathophysiology for arterial impingement/entrapment syndromes is thought to occur due to an abnormal anatomical relationship between the variant artery and adjacent anatomical structures resulting over time in intrinsic arterial occlusive damage due to repetitive microtrauma and subsequent premature atherosclerosis. Symptomatic features then manifest either due to local stenosis/occlusion or when unstable plaque leads to downstream atherothromboembolic phenomena. In this case, the impingement is from the interosseous membrane at the point of membrane perforation.

PRAES is clearly rare but awareness of the condition and comprehensive imaging to fully include the smaller vessels down into the feet is a prerequisite for diagnosis. The absence of classic

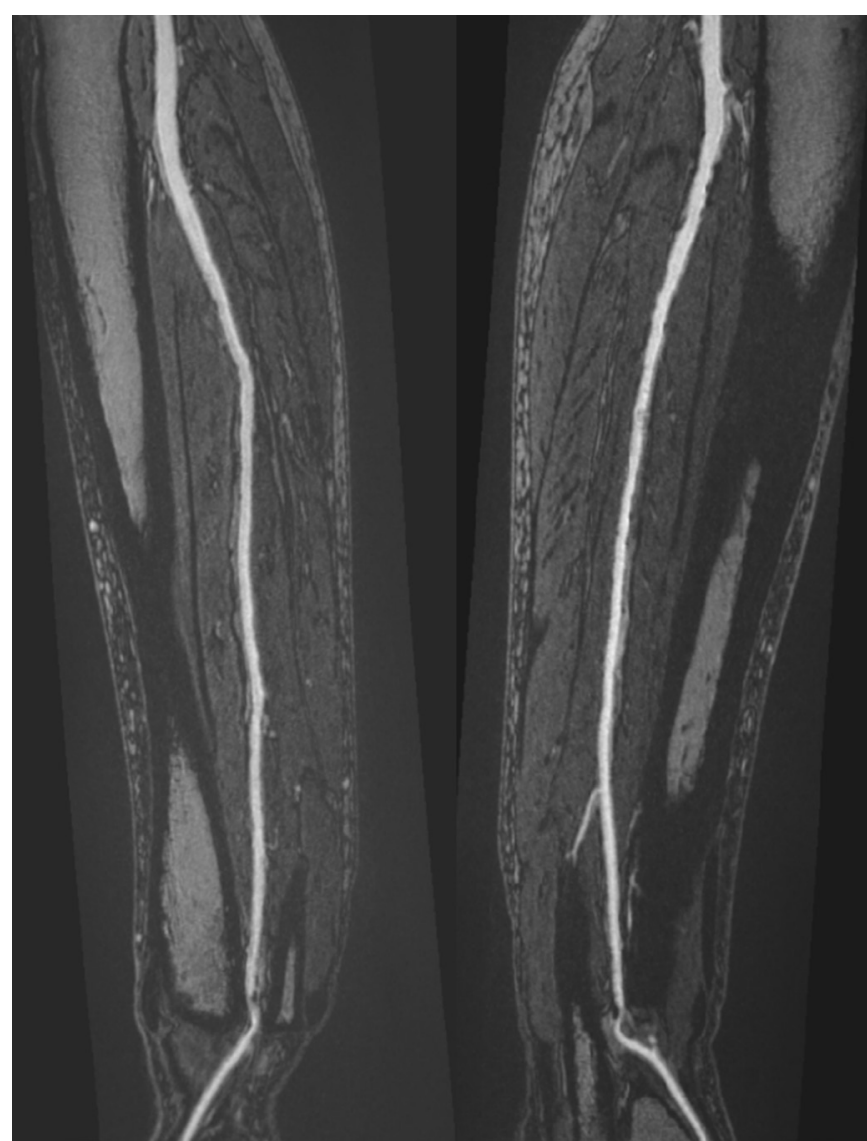

Figure 2 Curved multiplanar reformat high-resolution steady-state image - intrinsic arterial disease resulting in focal stenosis in both distal segments of the dominant peroneal artery that is worse on the left compared with the right.

signs and symptoms unique to the condition means that the diagnosis cannot be made on clinical examination alone necessitating vascular imaging. While conventional invasive arteriography would be able to make the diagnosis of a dominant peroneal artery and any stenosis, this invasive procedure with attendant risks would not identify and delineate the actual underlying anatomical cause as being due to vessel impingement. Computed tomographic angiography serves as a rapid diagnostic tool and could assess the anatomy needed for diagnosis of PRAES. However, tissue contrast discrimination for delineation of the small crural vessels from critical tendinous/ligamentous structures, especially in those subjects with little fat, is poor compared with MRI and the use of ionising radiation is a drawback for young patients.

Contrast-enhanced MRA is now widely available, well validated and a preferred modality for evaluation of lower limb occlusive arterial disease, recommended in several guidelines. ${ }^{67}$ The excellent soft tissue contrast and discrimination intrinsic to MRI in high-resolution steady-state imaging techniques enable detailed visualisation of the normal versus variant anatomies of the calf extremity vessels, vessel relations to the surrounding structures, and allows differentiation between intrinsic vascular disease from extrinsic compression causes. ${ }^{8}$ Besides being a non-invasive imaging modality, the absence of ionising radiation makes it particularly attractive for younger patients.

Thrombectomy or bypass options are not practical options for toe embolic complications caused by PRAES and balloon angioplasty would be problematic in view of the anatomical 
impingement. In our patient, we elected to optimise the antiplatelet regime to prevent further embolic episodes.

In conclusion, we present a rare and unusual case of emboli to the toes due to a very distal cause as a result of peroneal artery impingement. Anatomical variations of the crural arteries are not uncommon and as illustrated in our case, attention should be paid to more peripheral potential sources of emboli. This case also emphasises the utility of MRA in the evaluation of the lower limb arteries helping to delineate their local anatomical relations.

\section{Learning points}

- Anatomical variants of the crural arteries are common and we recommend the modified Kim-Lippert classification for clinical description.

- Traditional sources of lower limb embolism include the heart and aorta but other peripheral causes like the lower limb arteries should always be borne in mind.

- Advanced MR angiography techniques such as time-resolved angiography and high-resolution steady-state sequences are useful in the assessment of lower limb arterial pathologies.

Contributors Both ABT and GR certify that we have participated sufficiently in the work to take public responsibility for the content, including participation in the concept, writing, revision and final approval of the manuscript. WS participated in the patient recruitment, manuscript review and revision process.

Funding The authors have not declared a specific grant for this research from any funding agency in the public, commercial or not-for-profit sectors.

Competing interests None declared.

Patient consent Obtained.

Provenance and peer review Not commissioned; externally peer reviewed.

\section{REFERENCES}

1 Noorani A, Walsh SR, Cooper DG, et al. Entrapment syndromes. Eur J Vasc Endovasc Surg 2009;37:213-20.

2 Oztekin PS, Ergun E, Civgın E, et al. Variants of the popliteal artery terminal branches as detected by multidetector ct angiography. Open Med 2015;10:483-91.

3 Lippert H, Pabst R. In: Arterial variations in man: classification and frequency. Bergmen Munchen JF., editor. Verlag 1985.

4 Kim D, Orron DE, Skillman JJ. Surgical significance of popliteal arterial variants. A unified angiographic classification. Ann Surg 1989;210:776-81.

5 Kil SW, Jung GS. Anatomical variations of the popliteal artery and its tibial branches: analysis in 1242 extremities. Cardiovasc Intervent Radiol 2009;32:233-40.

6 Scottish Intercollegiate Guidelines Network (SIGN)2010 Diagnosis and management of peripheral arterial disease: a national guideline. Edinburgh: SIGN.

7 National Institute for health and care excellence (NICE). Peripheral arterial disease: Diagnosis and management. London: NICE, 2012.

8 Roditi G, Christie A, Chandramohan S. Lower-limb magnetic resonance angiography: performance of extracellular contrast agents versus blood pool contrast agent for both dynamic and high spatial resolution imaging in extended phase. Clin Radiol 2016;71:1296-303.

Copyright 2019 BMJ Publishing Group. All rights reserved. For permission to reuse any of this content visit

https://www.bmj.com/company/products-services/rights-and-licensing/permissions/

BMJ Case Report Fellows may re-use this article for personal use and teaching without any further permission.

Become a Fellow of BMJ Case Reports today and you can:

- Submit as many cases as you like

- Enjoy fast sympathetic peer review and rapid publication of accepted articles

- Access all the published articles

- Re-use any of the published material for personal use and teaching without further permission

For information on Institutional Fellowships contact consortiasales@bmjgroup.com

Visit casereports.bmj.com for more articles like this and to become a Fellow 